\title{
Correspondence
}

\section{Apnoea of immaturity}

Sir,

We fully appreciate the difficulties encountered by Jones $^{1}$ when conducting a randomised trial in a busy neonatal intensive care unit. We also recognise the need for proper evaluations of different treatments. However, the conclusion that 'CPAP was less effective than theophylline' is not fully proved from the data, though it may well be the case.

Dr Jones admits that the continuous positive airways pressure (CPAP) group had suffered significantly more perinatal complications than the infants in the theophylline group. Obviously this is a weak point in her study, but a more serious one is the dependency on nursing observations of apnoea in the majority of her cases. Stein and Shannon ${ }^{2}$ have pointed out the dangers of such dependence. To use such subjective records in statistical analyses is potentially misleading. In summary we do not think that the evidence reported substantiates her conclusions.

\section{References \\ 1 Jones R A K. Apnoea of immaturity. 1. A controlled trial of theophylline and face mask continuous positive airways pressure. Arch Dis Child 1982; 57: 761-5. \\ 2 Stein I M, Shannon D C. The pediatric pneumogram: a new method of detecting and quantitating apnoea. Pediatrics 1975; 55 : 599-603.}

J K STOTHers AND V VAN SOMEREN Joint Academic Department of Child Health, London Hospital Medical College, Turner Street, London E1 $2 A D$

\section{Dr Jones comments:}

It was indeed unfortunate that despite randomisation, the infants in the CPAP group had significantly more perinatal complications than those in the theophylline group. Nevertheless, I found no correlation between the perinatal complication score and the response to treatment, and as described in my paper, multiple co-variance analysis showed a significant treatment effect even after any effect of pre-treatment rates of apnoea and perinatal complications had been removed.

Stothers and van Someren also question the validity of using nursing observations which are known to be inaccurate. The greater reduction in bradycardias for infants given theophylline rather than CPAP was confirmed, however, by the continuous recordings in the latter part of the study. In these later infants, I compared the continuous recordings directly with the nurses' observations and found, as have many other authors, that nurses underestimated the number of attacks, but there was no significant difference in the degree of underestimation between infants on theophylline and those on CPAP. Ideally all infants would have had continuous recordings, but I do not consider that lack of these negates the overall conclusion that in very immature infants theophylline is more effective than CPAP in the treatment of apnoea.

\section{Estimation of glomerular filtration rate from height/plasma creatinine ratio}

Sir,

In the August issue, two papers discuss the reliability of the height/plasma creatinine $\left(\mathrm{Ht} / \mathbf{P}_{\mathrm{Cr}}\right)$ ratio as an estimate of glomerular filtration rate (GFR). Both studies used the plasma disappearance curve of ${ }^{51} \mathrm{Cr}$-EDTA as a reference for the estimation of GFR, and reached contradictory conclusions. While Morris et al. ${ }^{1}$ found the $\mathrm{Ht} / \mathbf{P}_{\mathrm{Cr}}$ ratio 'a clinically useful aid to the estimation of renal function,' Davies et al., ${ }^{2}$ by contrast, concluded that 'the prediction of GFR in children from single $\mathrm{Ht}$ and $\mathbf{P}_{\mathbf{C r}}$ measurements was of limited value in clinical practice'.

In a commentary to these findings, Dr Barratt discusses the drawbacks of the estimation of GFR by the analysis of the plasma disappearance on a single compartmental model and emphasises that it is 'somewhat hazardous to assess other methods of estimating GFR by comparing them with the plasma clearance of ${ }^{51} \mathrm{Cr}$-EDTA. From Dr Barratt's assertion that 'the clearance of inulin remains the definitive estimate of GFR', it can be inferred that other methods for the estimation of GFR should preferably be compared to the standard inulin clearance.

This is precisely what we did in a retrospective analysis of 500 inulin clearance studies in children older than one year. ${ }^{3}$ All tests were performed during the years 1972 to 1979 and included routinely the assessment of inulin, para-amino-hippuric acid, creatinine, and urea clearances. Each clearance was expressed as the mean of 4 to 5 consecutive clearance periods obtained over 3 hours.

Seventy-two out of the 500 children were selected according to their standard inulin clearance, in order to obtain a group of patients whose inulin clearance values were uniformly distributed throughout the range from 5 to $160 \mathrm{ml} / \mathrm{min}$ per $1.73 \mathrm{~m}^{2}$.

The Figure shows the correlation that we observed between inulin clearances and the $\mathrm{Ht} / \mathrm{P}_{\mathrm{Cr}}$ ratios. The slope of the regression line was significantly different from that of the line of identity $(P<0.001)$. Calculated values using the expression $0.55 \mathrm{Ht} / \mathrm{P}_{\mathrm{Cr}}$ underestimated inulin clearance values at GFR above $80 \mathrm{ml} / \mathrm{min}$ per $1.73 \mathrm{~m}^{2}$, and overestimated them below 80 . In addition, dispersion of the individual points around the regression line was substantial. We thus found little merit in the use of $\mathbf{H t} / \mathbf{P}_{\mathrm{Cr}}$ ratios as an estimate of GFR. 